\title{
Opening the black box: knowledge creation in data teams
}

\author{
Mireille D. Hubers, Cindy L. Poortman, Kim Schildkamp and \\ Jules M. Pieters \\ University of Twente, Enschede, The Netherlands, and \\ Adam Handelzalts \\ VU University Amsterdam, Amsterdam, The Netherlands
}

\begin{abstract}
Purpose - In this study, Nonaka and Takeuchi's socialization, externalization, combination and internalization (SECI) model of knowledge creation is used to gain insight into the process of knowledge creation in data teams. These teams are composed of school leaders and teachers, who work together to improve the quality of education. They collaboratively create knowledge related to data use and to an educational problem they are studying. The paper aims to discuss these issues.

Design/methodology/approach - A qualitative micro-process case study was conducted for two data teams. The modes, transitions and content of the knowledge creation process were analyzed for all data team meetings over a two-year period. In addition, all team members were interviewed twice to triangulate the findings.

Findings - Results show that the knowledge creation process was cyclical across meetings, but more iterative within meetings. Furthermore, engagement in the socialization and internalization mode provided added value in this process. Finally, the SECI model clearly differentiated between team members' processes. Team members who engaged more often in the socialization and internalization modes and displayed more personal engagement in those modes gained greater and deeper knowledge.

Research limitations/implications - The SECI model is valuable for understanding how teams gain new knowledge and why they differ in those gains.

Practical implications - Stimulation of active personal engagement in the socialization and internalization mode is needed.

Originality/value - This is one of the first attempts to concretely observe the process of knowledge creation. It provides essential insights into what educators do in professional development contexts, and how support can best be provided.
\end{abstract}

Keywords Professional learning, Teams, Data teams, Knowledge creation,

Professional learning community, SECI model, Qualitative research

Paper type Research paper

Data-based decision making in education has been emphasized globally in recent years (Datnow et al., 2013). Data-based decision making entails the collection and organization of data that are subsequently used to help improve the educational quality of individual teachers, schools or districts (Lai and Schildkamp, 2013). These data can represent aspects of students, teachers, parents and/or schools and can be both quantitative and qualitative. Examples are students' achievement scores and observations of classroom teaching.

Data-based decision making, or data use, is more likely to be effective than decisions based on intuition and experience (Schildkamp and Poortman, 2015). Furthermore, data

The authors are grateful to the Dutch Ministry of Education, Culture and Science for funding the data teams project. Although government funded, the present study was independently designed and conducted.

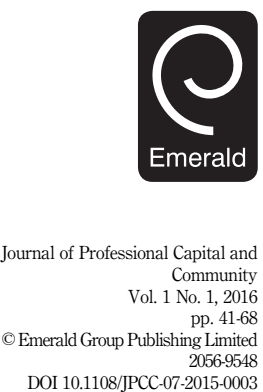


JPCC 1,1

can support teachers' processes of reflection and provide insight into their strengths and weaknesses. As a result, teachers may change their behavior, such as by trying out different instructional strategies, which can improve their own performance (Schildkamp and Kuiper, 2010) and lead to improved student achievement (Campbell and Fullan, 2006; Carlson et al., 2011; Lai et al., 2009).

Despite the benefits of data use, most teachers do not use data to the best effect or do not use data at all (Schildkamp and Teddlie, 2008). One promising way to increase the use of data is to set up data teams within schools (Wayman et al., 2006). Data teams can be considered as professional learning communities. One of their aims is to create professional capital, which refers to collective, interdependent professional learning (Hargreaves and Fullan, 2012). Here, a data team refers to a group of educators who collaboratively learn to use data to examine and improve the quality of education through the "data team procedure" (Schildkamp et al., 2015).

Insight into such a process of knowledge creation is scarce and often relies on selfreports of positive impacts (e.g. De Vries and Pieters, 2007; McFadyen and Cannella, 2004; Van den Bossche et al., 2011; Vescio et al., 2008), through which this process remains relatively unknown: a "black box." Studies of how teachers acquire knowledge about data use or what they actually do with data use in professional development contexts are substantially underdeveloped (Little, 2012; Gerzon, 2015). Therefore, this paper explores the micro-process of knowledge creation in two secondary schools that implemented the data team procedure.

\section{Theoretical framework}

The theoretical framework for this paper addresses the relationship between the knowledge creation process and the data team procedure.

\section{The data team procedure}

Data teams, in the context of this study, are professional learning communities which consist of six to eight people at the same school: a school leader, several teachers and, if possible, the quality manager, who has access to the data (Schildkamp et al., 2015). Together, they learn how to use data to solve an educational problem at their school, such as high grade retention rates. On average, the data team members meet twice a month for two years. They work following a structured cyclic procedure as illustrated in Figure 1, which includes an extensive set of guidelines and activities. A coach from the university guides them through the procedure. The goal of the data team procedure is to educate teachers and school leaders in data use. In addition, they learn how they can solve the educational problem they are facing, thereby improving the quality of education at their school. As a result, data team members need to gain knowledge about both data use and about the educational problem. Studying their process of knowledge creation is necessary in order to reveal how they gained this knowledge.

\section{The process of knowledge creation}

Among the many theories of knowledge creation (e.g. Engeström, 1999; Szulanski, 1996; Wenger, 1998), Nonaka and Takeuchi (1995) propose a four stage model of socialization, externalization, combination and internalization (SECI) where knowledge creation: "depends on tapping the tacit and often highly subjective insights, intuitions, and hunches of individual employees and making those insights available for testing 


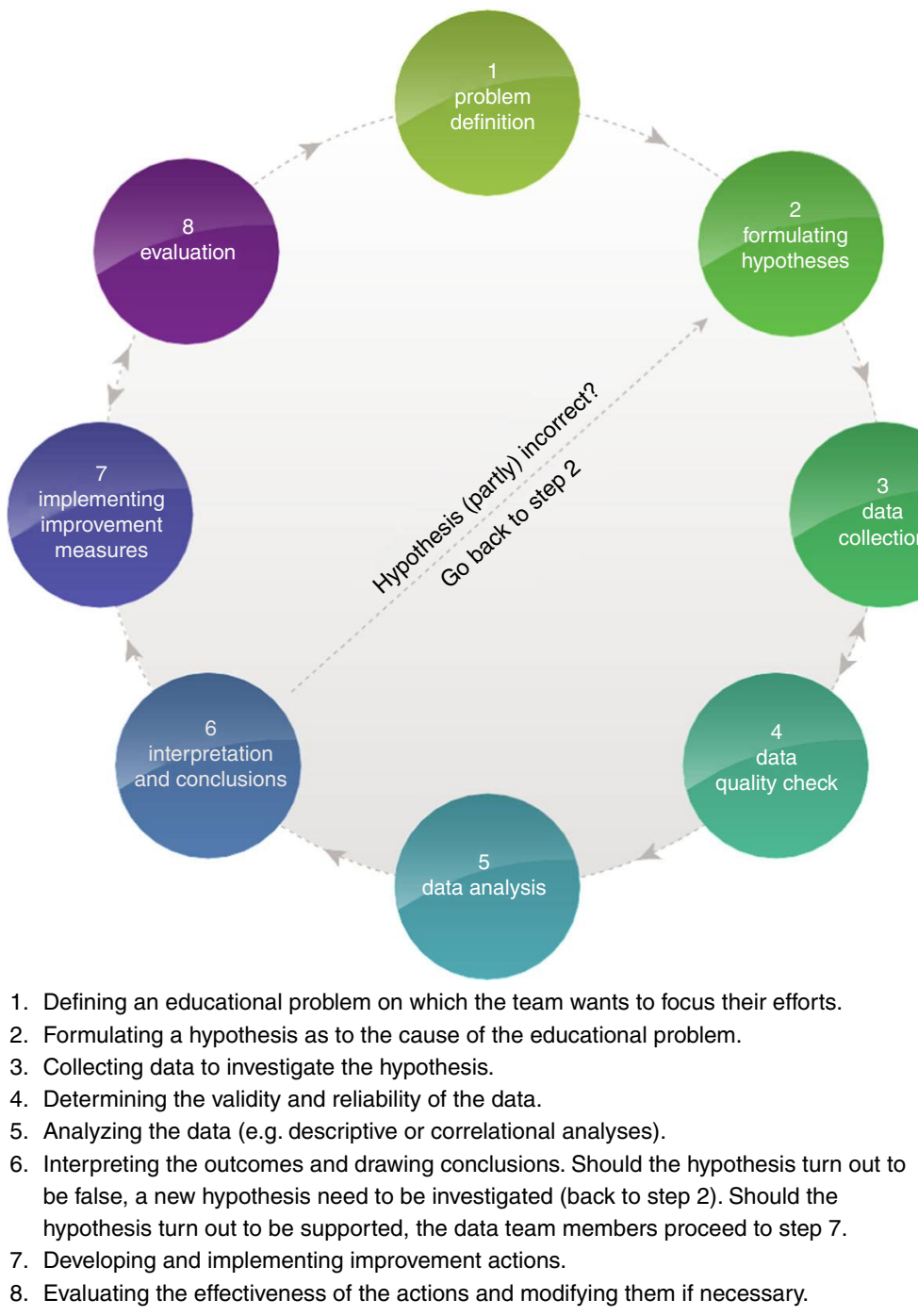

Source: Schildkamp and Poortman (2015)
Knowledge creation in data teams
Figure 1.

The data team procedure

and use by the company as a whole" (Nonaka, 1991, p. 97). Groups or individuals move through these four stages in a fixed order (Nonaka et al., 2008):

(1) In the socialization mode, tacit knowledge is shared, as through telling about one's own experiences, and observing experts.

(2) In the externalization mode, tacit knowledge of the socialization mode is made explicit through models, language, images and other forms of expression.

(3) In the combination mode, group members collect explicit knowledge and define and edit it into a more complex and systematic set of knowledge. 
JPCC

1,1

(4) In the internalization mode, group members critically reflect on the knowledge they created and put it into practice. Here, knowledge becomes the foundation for new routines.

These four modes are not equally important: the socialization and internalization mode are critical because they require an active involvement of the self, or personal commitment (Nonaka, 1991). When these two modes are not properly enacted, the externalization and combination modes cannot be properly taken up either. This results in a lack of progress and evanescent knowledge.

The SECI model is increasingly being used in educational science (e.g. Hargreaves, 1999; Schaap et al., 2009). In this study, the SECI model is drawn on in relation to the data team procedure where teachers and school leaders are expected to bring forward their intuitions about their educational problem to formulate a hypothesis, which is made available for testing. When conclusions are drawn, it may turn out that these intuitions are invalidated. For example, some teachers blame certain primary schools for students' poor achievement in the first year of secondary education. When data team members use data to test their intuitions and conclude that this poor achievement is not caused by those students' primary schools, for example, but by the use of learning materials that are poorly connected with each other, this can be a powerful learning mechanism (Schildkamp et al., 2015).

\section{Components of the knowledge creation process}

Research on how individuals or groups engage in the four SECI modes is scarce. For example, Yeh et al. (2011) found that pre-service teachers' professional knowledge significantly improved after all four modes had been worked through. However, it was unclear how or in what order individuals or groups actually engaged in these modes. Furthermore, it is as yet unknown whether all individuals or groups engage in the SECI modes in a similar manner, or whether differences in engagement can occur. To describe data team members' knowledge creation process in terms of the SECI model, the present study focussed on three components: modes, transitions and content.

The first component is the mode: for example, "socialization." It is theorized that the way in which one engages in the modes influences the knowledge creation process. For example, if engagement in one of the four modes is impeded, especially in the socialization and internalization modes, both the quality and quantity of knowledge may decrease (Nonaka, 1991; Nonaka et al., 2008).

The second component is the transitions between the modes. According to Nonaka et al. (2008), the modes are worked through in a fixed order: first socialization, then externalization, then combination and finally internalization. However, other transitions might be possible in practice, as previous research indicated that data use may not be a linear process, but have a more iterative character (Mandinach, 2012; Marsh, 2012; Schildkamp and Poortman, 2015). This study asks what activities occur when data team members make a transition from working in one mode to another, considers whether transitions exist between all modes, and whether some transitions are more common than others. Combining the first two points, this study asks how data team members create knowledge in terms of the modes and transitions of the SECI model.

The third component of the knowledge creation process is the knowledge content. The data team procedure aims to address at least three types of knowledge content:

(1) Knowledge of the educational problem: this includes knowledge of what proved (not) to be the cause of the educational problem the data team members are 
working on (e.g. students lack studying skills), and knowledge of the design and implementation of the actions for improvement.

(2) Knowledge of data use as applied to the educational problem: this includes basic and practical knowledge of data use (e.g. knowing how to calculate certain grade retention rates).

(3) Knowledge of data use in general: this includes knowing when data are valid and reliable, and knowing how a hypothesis can be statistically tested. Knowledge of data use in general is more abstract than knowledge of data use as applied to the educational problem. This abstract knowledge is hypothesized to facilitate a deeper understanding of the data team procedure as such. Therefore, this content seems crucial for both successfully identifying needed data and drawing inferences from data in appropriate ways (Coburn and Turner, 2011), as well as making a transfer to other decision-making activities outside the context of the data team (e.g. the teacher's own instructional purposes).

Bringing together these three types of knowledge content, this study considered how knowledge of the educational problem, data use as applied to the educational problem and data use in general resulted from the data team members' knowledge creation process, among with how this related to the knowledge creation process in terms of modes and transitions.

\section{Method}

Context

This qualitative case study took place in the Netherlands. In 2009, approximately 20 percent of Dutch secondary schools used data in their decision making (Dutch Inspectorate of Education, 2010). A target has been set to increase this figure to at least 90 percent by 2018 (Verbeek and Odenthal, 2014). Because of this, schools increasingly prioritize data use.

Dutch schools have considerable freedom in determining what subject matter they teach and what textbooks, assessments and instructional strategies they use (Kuiper et al., 2006). However, Dutch legislation holds schools increasingly accountable for ensuring their educational quality. As a result, data team members often choose to work on an educational problem that is the Inspectorate's point of concern. Furthermore, schools' freedom in structuring students' educational experience also implies that data team members have considerable freedom in designing improvement measures. These measures can vary from changing their school's grade retention policy to changing instructional strategies or textbooks.

The present study was part of a larger project funded by the Dutch Ministry of Education. In total, 25 secondary schools voluntarily signed up for this project by sending in a preliminary general statement of a problem on which they wanted to focus their efforts. Ten schools were selected based on this problem statement and their geographical location, so that various types of problem statements and various parts of the Netherlands were represented. These schools worked with the data team procedure for two years. All data team members voluntarily participated. Each data team was supervised by the same coach who was not an author of this paper.

\section{Participants}

A case study was conducted at two schools, Fairview and Lincoln[1], that were selected from the group of ten schools because they were working on a similar problem 
JPCC 1,1 statement (grade efficiency rate[2]). This helped to ensure that the knowledge content related to the educational problem had roughly the same scope in both teams.

Both Fairview and Lincoln are Protestant schools for secondary education. Fairview provides education in the lowest Dutch educational track[3]. It has four locations; personnel from two of these worked collaboratively in one data team. A total of 543 students (ages 12-16) attend Fairview 1, and 464 students (ages 12-16) attend Fairview 2. Both rates are slightly below the Dutch average for this specific school type. The team was initially composed of four members from Fairview 1 and three members from Fairview 2. Prior to the formation of the data team, team members only knew and had collaborated with their colleagues from their own location. In addition, team members from Fairview 1 had informal contact with each other outside the school context before formation of the data team.

Lincoln provides education in all three Dutch educational tracks. A total of 1,261 students (ages 12-18) attend this school, which is slightly above the Dutch average for this specific school type. The Lincoln data team was composed of seven members. See Table I for more information on all data team members.

\section{Instruments}

Observations. All team meetings over the course of the two-year data team project were audiotaped by the coach, and transcribed verbatim. This resulted in transcripts for 24 meetings for Fairview and 21 meetings for Lincoln.

Interviews. All data team members who participated in their team for both years were individually interviewed at the end of each year, see Table I. In relation to the content of the knowledge creation process, team members were asked to describe what they had gained from their participation and what they considered to be learning points.

\begin{tabular}{|c|c|c|c|c|}
\hline Name & Location & Years of experience & Function & Subjects \\
\hline \multicolumn{5}{|l|}{ Fairview } \\
\hline Mr Anderson $^{\mathrm{a}}$ & 1 & 20 & Teacher, school leader & Dutch \\
\hline Mr Johnson $^{\mathrm{a}}$ & 1 & 12 & Assistant principal & - \\
\hline Ms Smith ${ }^{\mathrm{a}}$ & 1 & 9 & Teacher & English \\
\hline Mr Williams $^{\mathrm{a}}$ & 1 & 8 & $\begin{array}{l}\text { Teacher, quality } \\
\text { manager }\end{array}$ & Science, Chemistry \\
\hline Mr Garcia & 2 & 7 & Teacher & Science, Chemistry \\
\hline Mr Jones & 2 & 35 & Teacher, school leader & Mathematics \\
\hline Ms Lee & 2 & 10 & Teacher & History, Geography \\
\hline Mr Miller & 2 & 31 & Teacher, school leader & Mathematics \\
\hline Ms Rodriguez & 2 & 15 & $\begin{array}{l}\text { Teacher, quality } \\
\text { manager }\end{array}$ & $\begin{array}{l}\text { Fashion and Commerce, } \\
\text { Trade and Sales, Economics }\end{array}$ \\
\hline \multicolumn{5}{|l|}{ Lincoln } \\
\hline Ms Brown ${ }^{\mathrm{a}}$ & - & 32 & Teacher & Music, Arts \\
\hline Ms Clark ${ }^{\mathrm{a}}$ & - & 13 & Supporting staff & - \\
\hline Ms Harris ${ }^{\mathrm{a}}$ & - & 30 & School leader & - \\
\hline Mr Martinez & - & 15 & Teacher & Mathematics \\
\hline Mr Thomas ${ }^{\mathrm{a}}$ & - & 5 & Supporting staff & - \\
\hline Mr Wilson ${ }^{\mathrm{a}}$ & - & 9 & Teacher & Chemistry \\
\hline Ms Young ${ }^{\mathrm{a}}$ & - & 20 & Teacher & Mathematics \\
\hline
\end{tabular}

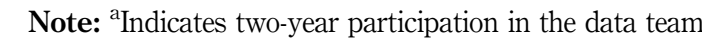

\section{Table I.}

Participants' characteristics 
Data analysis

Observations. A coding scheme was developed as presented in Table II, which was inspired by previous research on the SECI modes and on similar inquiry activities (e.g. Hakkarainen et al., 2004). The coding scheme encompassed the four SECI modes and the three types of knowledge content. Two codes needed to be applied in Atlas.ti per segment of the team meeting: one for the mode and one for the content. Transitions between modes were not part of the coding scheme, but were traced in the next phase of the analyses.

In this next phase, a thick description (Geertz, 1973) of the team's knowledge creation process was made for each meeting. This description included all three components of the process: the modes, transitions and the content. Each time a new mode was coded (e.g. from socialization to externalization), the transition was traced. The conversation around this transition was explored in detail to determine who or what initiated the transitions between the modes. This information was included in the thick description.

Furthermore, the thick descriptions were accompanied by a graph that visually represented the modes, transitions and content, which gave a quick overview of the course of the meeting; see Figure 3 for an example. After that, the thick descriptions were summarized. When a SECI mode was dominant throughout consecutive meetings, those meetings were combined into one summary. A within-case analysis was conducted on the summaries to describe the knowledge creation process in terms of the modes, transitions and content both within and between data team meetings for each school. After that, a cross-case analysis was conducted to describe similarities and differences between the two data teams' knowledge creation processes in terms of the modes, transitions and content.

To determine inter-rater reliability, 10 percent of the meetings (five out of 45) were coded by the second author. This resulted in an inter-rater reliability of 0.67 for the SECI modes and 0.67 for the knowledge content, which is considered acceptable (Eggen and Sanders, 1993).

Interviews. The responses of the individual data team members were summarized by knowledge content and by data team to facilitate within-case and cross-case analyses. Quotes were translated from Dutch to English to illustrate claims made by particular team members. Their responses were used to triangulate findings for the modes and knowledge content. This ensured the construct validity of the findings (Yin, 2009).

\section{Results Fairview}

Team Fairview's process of knowledge creation was studied over 24 meetings. During the first meeting, the coach explained the data team procedure and made practical agreements with the team members. Therefore, this meeting did not include relevant information on knowledge creation regarding the educational problem or data use. The process of knowledge creation in the remainder of Fairview's meetings will be described below; see also Figure 2.

\section{Modes}

Meetings 2-9: quantitative research. During the first four meetings, the data team members brainstormed about which grade levels to include in their study of grade demotion[4] and what hypothesis they wanted to test first (socialization). Together with their coach, they decided to study the lower grade levels. They also brainstormed about 


\section{school}

Externalization Data team members prepare or perform activities such as collecting information, observing, using surveys or contemplating experts. They define terms, concepts and meanings

Combination Data team members draw conclusions, and the resulting knowledge has the potential to be shared immediately with colleagues. This includes accepting or rejecting hypotheses. They translate knowledge into concrete products, solutions or policies. They use logic to solve contradictions

Internalization Data team members discuss what knowledge was important or unexpected, or discuss the strengths and weaknesses of their theory. They practice or gain experience
"Let's ask the principal "Here, you see that "You cannot just why students cannot $60 \%$ is below the repeat a grade" desired level" "So, we are satisfied "The Inspectorate when we achieve [...]" calculates grade reason to do so" retention like this" "A t-test is [...]"

"In the literature it is stated that [...]" "Our pupils say we

"We come to the conclusion that our have enough pupils data cannot to perform reliable have to be more strict. confirm our So, the teachers have to hypothesis" check their homework "If we administer each lesson" this survey each "Let's think, why is our year, we can flag hypothesis rejected for who is at risk for this year?" grade repetition" "What effect does the change in our school policy have on our data?" analyses" "If all teachers keep track of their grades like this, we can perform $t$-tests like this in the future" "How can this significant correlation result in a non-significant result on the T-test?"

"I never knew the difference between

"Our computer boys and girls was this program offers large" program offers "Let's take this test ourselves, to see what our pupils need to master" to frame our

problem than I was aware of"

"We are not surprised by our data"

"If you do this and I do that, we will all learn how to collect data"
Table II.

Coding scheme 
Knowledge

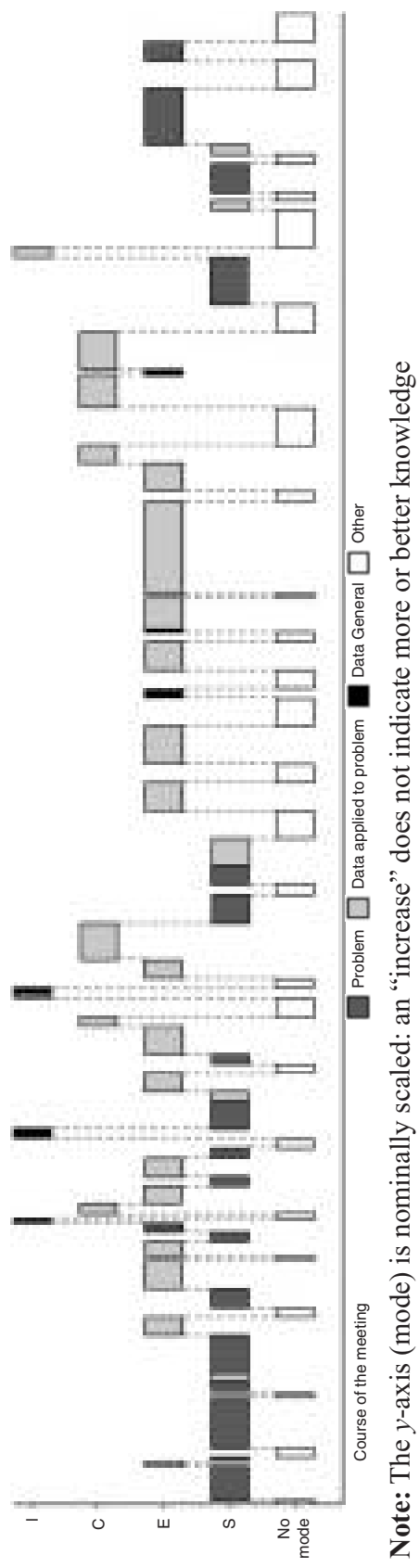
creation in data teams

Figure 2.

The process of knowledge creation in team Fairview 
JPCC 1,1

what data would be available to study their hypothesis, and provided each other with background information on their school's policy on grade demotion. For example, one data team member stated: "In 2008/2009, our grade demotion rates increased to a poor level. Do you know if our policy changed that year?" Together, the team members decided to first determine whether students' final test scores from primary school were associated with grade demotion in secondary education.

In their fifth meeting, team members shared information on their school's policy on grade demotion and discussed their own experiences and beliefs on this issue (socialization). They also discussed a data file on students' test scores for their first hypothesis (externalization). For example, one data team member explained: "I looked at the test score data over the past three years [...], and here you see the results. [...] I have to note, that for quite a few students, there is no test data available." The coach noted that these data did not quite represent what they wanted to know, which led to a discussion about their validity. Finally, the team members brainstormed about their second hypothesis: determining whether primary schools recommended the proper educational track placement for their students[5] (socialization). At the end of the meeting, they briefly reflected on their progress (internalization). One member stated: "I believe our inquiring attitude is increasing."

From the sixth through the eighth meetings, team members discussed and revised their data files on students' test scores and on primary schools' recommendations (externalization). At first, they believed it was not necessary to determine the reliability of their data. As one member said: "These data are partly delivered by our own school, and partly by the primary schools. [...] The only question is how you deal with statements based on one or two students. [...] I think that is not reliable. But how we got these data, that is reliable." However, it quickly became apparent that there were still some errors in the file. After correcting this, they concluded that students' primary school test scores were not associated with grade demotion (brief engagement in combination mode).

During their ninth meeting, they concluded that many primary schools gave poor advice about their students, thereby increasing the grade demotion rates in secondary education (brief engagement in combination mode). They reflected on whether or not they were surprised by their results (internalization). For example, one team member stated: "I already expected that some primary schools would increase our grade demotion rates. But, that so many of them increase our rates, that surprises me." The team members decided not to develop improvement measures, as the principal had already taken action to solve this problem. Starting in the following year, primary schools would have to give an unequivocal recommendation for one specific educational track, instead of combining two educational tracks in their recommendation. Instead, the team members brainstormed about a new hypothesis they could study (socialization).

Meetings 10-24: qualitative research. During the tenth meeting, team members decided that they wanted to conduct interviews to find out what students themselves believed to be the cause of their grade demotion. With the help of their coach, they brainstormed about which students they should interview, and what the broad outline of their interview schedule should be (socialization).

During the 11th and 12th meetings, they made decisions about conducting the interviews (e.g. which students, issues of anonymity and privacy), and agreed upon the content of the interview schedule (externalization). During meetings 13 and 14, the team 
members discussed the pilot interviews they had conducted (externalization). Among other things, they determined the quality of their data: they evaluated their role during the interviews, and discussed the comparability of their interviews. For example, one team member stated: "We did not diverge from the interview schedule," to which another member responded: "I think you did it right, because then we can compare answers with each other and ultimately, that is what we want." During meetings 15 through 18, the data team members developed a coding scheme, applied it to their data and reviewed its inter-rater reliability (externalization).

During the 19th meeting, the coach explained how conclusions could be drawn from the qualitative data (externalization). Furthermore, some small coding errors were corrected. Team members drew their conclusions about their data in the 20th meeting (combination). Among other things, they concluded that students who had been demoted to a lower educational track indicated that their counselors did not really help them, that teachers' instructions were not always clear, and that teachers' classroom management was poor.

These conclusions were used in the 21st and 22nd meetings, during which team members brainstormed about possible measures to improve their grade demotion rates, and what data would be necessary to monitor the effectiveness of these measures. In doing so, they briefly reflected on data use in general and listed the positive effects of the data team procedure (internalization). One member stated: "I think this is a nice side effect of the data team: it also gives you insight into your own performance."

During their final two meetings, the 23rd and 24th, the team members selected a few actions to take and made them more specific with the help of their coach (externalization). For example, they agreed to disseminate a questionnaire and a peer-observation instrument to determine teachers' classroom management skills.

In general, the data team members were engaged in the socialization and externalization modes in almost every meeting. In the socialization mode, they shared their tacit knowledge by telling each other about their own intuitions and experiences. They did this in three main ways: by brainstorming about hypotheses, providing each other with background information on their schools' policy on grade demotion and brainstorming about possible actions.

In the externalization mode, team members made their knowledge from the socialization mode more explicit. This was primarily done by discussing what measurements and data needed to be collected for what cohorts, and how those had to be processed. Determining the reliability and validity of their data was another, but less frequent, activity in this mode. Initially, they took this more or less for granted; for example in meeting 8 they believed that data from their school's administrative system is always reliable. Over time they evaluated the quality of their data more thoroughly; for example in meeting 14 they discussed how they could ensure the comparability of their interviews.

In the combination mode, the data team members defined a complex set of knowledge by drawing conclusions about data they had analyzed. This mode was hardly dominant, but they were briefly engaged in this mode in six meetings; for example in meeting 9 they concluded that primary schools' recommendations increased grade demotion rates in secondary education.

The internalization mode was never dominant, but the team members engaged briefly in this mode in eight meetings. When engaged in this mode, they reflected on whether or not they were surprised by their findings, on data use in general and on
Knowledge creation in data teams 
JPCC 1,1

their own learning process. For example, during the 21st meeting, they reflected on data use and listed the positive outcomes of the data team procedure.

Transitions. Initially, the transitions between modes that occurred between meetings were more or less cyclical; thus, going from socialization, to externalization, to combination and finally to internalization. Furthermore, these transitions were quite in line with the steps of the data team procedure. Team members engaged in the socialization mode to brainstorm about their hypothesis (steps 1-2 of the data team procedure), engaged in the externalization mode to collect and analyze data (steps 3-5) and engaged in the combination mode to draw conclusions (step 6). This cycle was noticeable, regardless of whether quantitative or qualitative data were used.

However, concentrating on particular meetings shows that the process of knowledge creation is far more iterative within meetings; see, for example, Figure 3. Therefore, these "micro transitions" within meetings were studied. Transitions between all modes occurred, but some were more dominant than others. Only dominant transitions will be described here.

Within meetings, transitions from the socialization mode to the externalization mode and vice versa were most dominant. These transitions occurred when data team members provided each other with background information on the school's policy on grade demotion, shared their personal experiences with these issues, or brainstormed about a new hypothesis after the previous one was tested; that is, while collecting, analyzing or discussing their data files. These transitions were initiated by both the data team members and the coach.

Transitions from the combination mode to the externalization mode occurred when conclusions were being drawn about the data; while checking the quality of their data file, for example, by discussing whether a code was wrongfully applied to an excerpt. These transitions were most often initiated by the data team members.

Transitions from the internalization mode to the externalization mode occurred after the team members reflected on their learning process or about whether they were surprised by their findings; that is, while discussing their data files. These transitions were most often initiated by the team members.

Content. Overall, content related to the educational problem and to data use as applied to the educational problem was discussed to an equal extent during the meetings. Content related to data use in general was rarely discussed. Each type of knowledge content was addressed in all four modes, and was associated with its own dominant mode.

Content related to the educational problem was most often discussed in the socialization mode. During the interviews, the data team members explained that they gained knowledge about the impact of students' final test scores and recommendations from primary school on grade demotion in secondary education. Furthermore, they learned that students did not receive the support they wanted from their teachers and counselors, and that students believed some teachers had poor classroom management skills.

Content related to data use as applied to the educational problem was mainly discussed in the externalization mode. During the interviews, team members indicated that they were surprised by the honesty of their students and how well the students were able to critically reflect on themselves.

Content related to data use in general was most often discussed in the externalization mode, but was also discussed relatively often in the socialization and 
Knowledge creation in

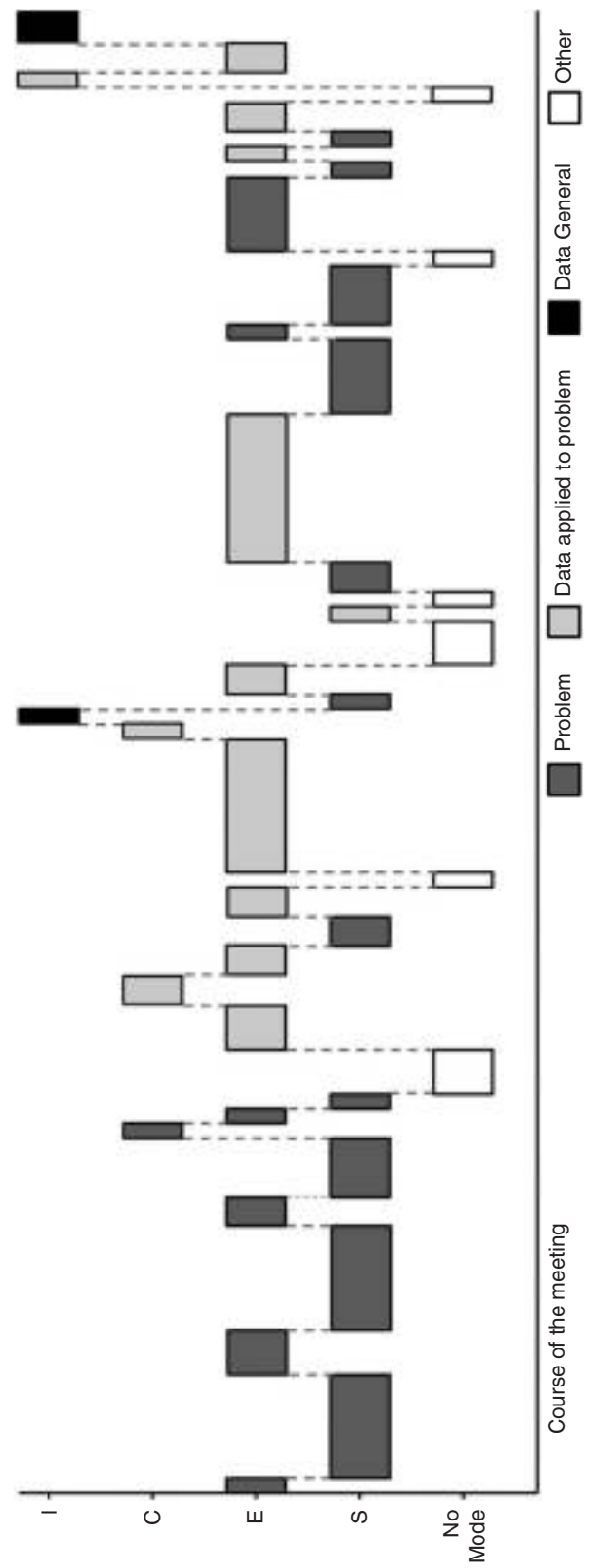
data teams

53

Figure 3.

The process of knowledge creation in team Fairview, meeting 5 
JPCC 1,1

54 internalization modes. During the interviews, the data team members indicated that they learned how important it is to use data for decision making. Beyond that, they gained knowledge about working with the data team procedure. For example, Mr Johnson said during the interview: "You use and develop research skills. Am I doing the right things? What do I want to achieve with this?" Furthermore, they found out that the quality of their data was not guaranteed, and that considerable effort needs to be spent on specifying a hypothesis and ensuring the validity and reliability of the data. For example, Mr Anderson noted in reference to the eighth meeting: "I thought that the data you get from your computer is right. But it appeared that some schools were registered multiple times under a different name, and that you really have to review the quality of your data. That was an eye-opener!"

Overall, data team members most often discussed content related to the educational problem and to data use as applied to the educational problem. However, this was not reflected in their knowledge gains. During the interviews, team members indicated that they had gained only some knowledge about data use as applied to the educational problem. They gained most knowledge about the educational problem and about data use in general, even though the latter content was rarely discussed. The differences in learning gains between data use as applied to the educational problem on the one hand and the educational problem and data use in general on the other hand became apparent in the number of examples of new knowledge they could list, and the depth of these examples (e.g. honesty of students vs the quality of data). Thus, the overall extent to which certain content was discussed was not necessarily indicative of what knowledge data team members gained. Rather, the extent to which this content was discussed specifically in the socialization and internalization mode seemed more indicative. Content related to the educational problem and to data use in general were more often addressed in these cases than content related to data use as applied to the educational problem. Thus, engagement in the socialization and internalization modes seemed to have an added benefit for gaining new knowledge.

\section{Results Lincoln}

The process of knowledge creation was also studied in a second case, team Lincoln, whose members worked on the educational problem during 21 meetings. During the first meeting, the coach explained the data team procedure and made practical agreements with the team members. Therefore, this meeting did not include relevant information on knowledge creation regarding the educational problem or data use. The process of knowledge creation in the remainder of Lincoln's meetings will be described below; see also Figure 4.

\section{Modes}

Meetings 2-8: quantitative research. During the second meeting, team members brainstormed about which grade levels to include in their study of grade retention, but struggled with this. Instead, they discussed several hypotheses they could study and brainstormed about what kind of data they needed to collect (socialization).

In the third meeting, they tried to find out how the Dutch Inspectorate calculates grade efficiency rates (externalization). They also brainstormed about what problem statement they wanted to focus their efforts on and what data they wanted to collect (socialization). In so doing, they provided each other with background information on their school's policy on grade efficiency. For example, one member stated: "Meanwhile, 


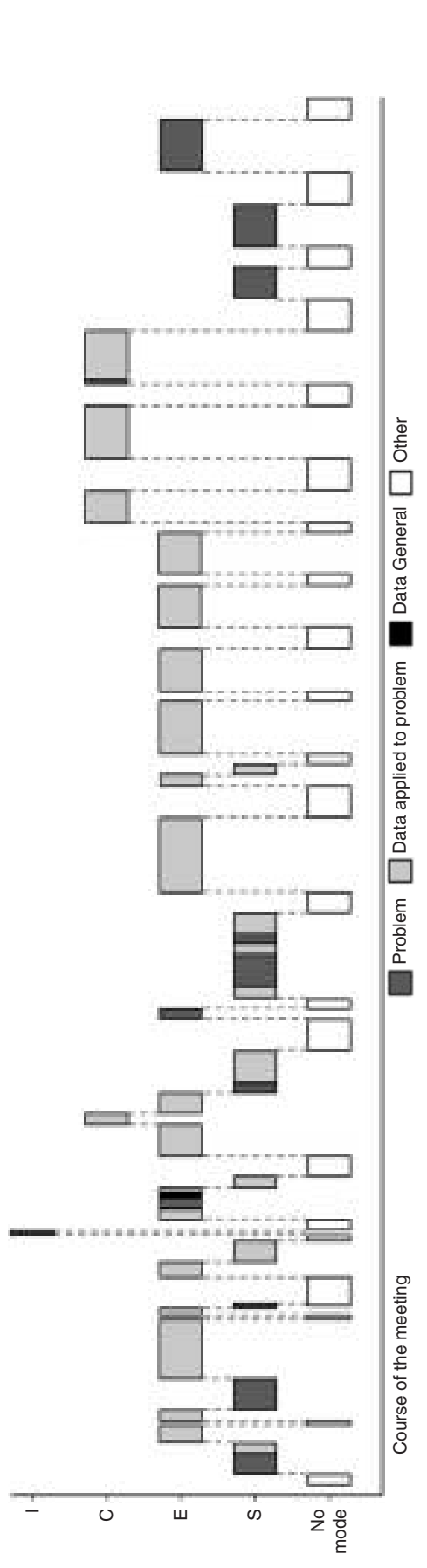

Knowledge creation in data teams

55

Figure 4. The process of knowledge creation in team Lincoln 
JPCC 1,1

our standards for determining who needs to repeat a grade have changed." With the help of their coach, team members eventually decided to study whether students' shortage points[6] for their core courses (Mathematics, Dutch and English) were associated with grade retention. Shortage points refer to the extent to which students' grades are below passing.

In their fourth meeting, the team members used data to define their problem statement (externalization). Furthermore, they discussed their data file on the core courses and discussed how it should be modified to match their hypothesis, for example, displaying whether or not a student repeated a grade level and how many grades below passing he/she had (externalization).

With the help of their coach, team members briefly evaluated their data file in the fifth meeting and concluded that the shortage points for the core courses were significantly associated with grade retention (externalization and combination, respectively). In doing so, they briefly reflected on their progress (internalization). As two members stated: "You want to go faster." "Yes, and obtain more information from it." After that, they brainstormed about whether or not they should also look at excess points[7]. This resulted in a brainstorm session on how they could compute this (socialization). In doing so, they provided each other with background information on their school's policy on grade retention.

In the sixth meeting, the team members discussed their data file (externalization). When the coach suggested reviewing the validity and reliability of their data, they briefly responded that this was not necessary. For example, one member said: "Yes, but when we keep being aware of that [...] at some point we have to move on." They briefly concluded that shortage points for the core courses were associated with grade retention (combination). After that, they brainstormed about what additional data they should collect (socialization), without finalizing the analyses related to their former hypothesis or formulating a new hypothesis.

The team members brought new data on slight variations of their first hypothesis (e.g. are shortage points for the main courses associated with grade retention?) to their seventh meeting. Ultimately, they concluded that shortage points for the main courses in Grades 8 and 9 were associated with grade retention (brief engagement in combination mode). They decided not to act upon their data, as they felt they did not yet know enough to design improvement measures. Therefore, during their eighth meeting they brainstormed about what additional data they wanted to collect (socialization). They were especially interested in conducting interviews, even though no explicit research question was posed.

Meetings 9-21: qualitative research. During the ninth meeting, the data team members brainstormed with their coach on what themes should be part of their interview schedule on grade retention (socialization). During the tenth and 11th meetings, they created this schedule, which included questions on, for example, students' motivation, course materials, their teachers and their situation at home (externalization).

In their 12th meeting they discussed their pilot test of this schedule and which students they should interview, and developed a coding scheme (externalization). They used their coding scheme in the 13th and 14th meetings, during which they determined the inter-rater reliability of the scheme with the help of their coach (externalization). In general, they almost immediately agreed with each other on which code was most appropriate. The reliability and validity of their data were discussed in 
the 15th meeting (externalization). The team members concluded that the quality of their data was ensured, as they had selected the appropriate students and each interview was conducted in the same setting. However, because they had interviewed only seven students, they were convinced that they could not use their data for taking action. In their opinion, it could only serve as a starting point for new quantitative research, regardless of what the coach said. For example, one data team member stated: "I feel very uncomfortable with this, using these data for measures."

During the 16th and 17th meetings, the team members drew their final conclusions about the interview data (combination). In so doing, they used their own experiences to frame their conclusions (brief engagements in socialization mode). Among other things, they concluded that students experienced a "culture shock" between grade levels, and that students believed their counselors did not provide them with enough support. The data team members briefly reflected on how data can undermine assumptions (internalization), and one team member stated: "What I like is that the assumptions that are discussed in the teachers' lounge [...] are not at all mentioned by our students."

After the coach convinced the data team members to use their qualitative data for improvement measures, the team members brainstormed about possible actions during the 19th and 20th meetings (socialization). For example, one data team member said: "We should offer professional development courses for our counsellors." In doing so, team members related possible actions to their own experiences. For example, "I have freshmen, and I clearly see their demotivation because of problems they ran into at the beginning of the year, and they keep running into those."

With the help of their coach, team members made their list of possible improvement measures more concrete during the 21st meeting (externalization). For example, they decided to have a particular meeting to inform students about what they could expect in the next grade.

In general, team members were engaged in the socialization and externalization modes in almost every meeting. In the socialization mode, they shared their tacit knowledge by telling each other about their own intuitions and experiences. They did this by brainstorming about what additional data could be collected. Toward the end, they also brainstormed about possible measures they could take to solve their educational problem.

In the externalization mode, the data team members made their knowledge from the socialization mode more explicit. This was mainly done by discussing what measurements and data needed to be collected for what cohorts, and how they had to be processed. The team members hardly ever engaged in this mode to discuss the reliability or validity of their data.

In the combination mode, the data team members defined a complex set of knowledge by drawing conclusions about data they had analyzed. This mode was hardly dominant, but they were (briefly) engaged in this mode in seven meetings; see, for example, meeting 16, during which they concluded that students experience a "culture shock" between grade levels.

The internalization mode was never dominant, but the team members briefly engaged in this mode in four meetings. When engaged in this mode, the data team members reflected on the data team procedure and their progress; see, for example, meeting 5.

Transitions. Transitions between meetings were more or less cyclical, and were quite in line with the steps of the data team procedure. However, concentrating on specific meetings showed that the process of knowledge creation was more iterative 
JPCC 1,1

within meetings; see, for example, Figure 5. Transitions occurred between nearly all of the modes, the exceptions being transitions between the internalization mode and socialization or combination mode (and vice versa), which did not happen. However, some transitions were more dominant than others. Only the dominant transitions will be described here.

Overall, transitions from the socialization mode to the externalization mode and vice versa were most dominant. Team members brainstormed about their problem statement or about what additional data they wanted to collect; that is, while preparing research activities (e.g. creating a coding scheme) or discussing data files or analyses. Most of these transitions were initiated by the data team members.

Transitions from the combination mode to the socialization mode also occurred relatively often. These transitions were made to frame (tentative) conclusions about team members' own experiences. Therefore, these transitions were always initiated by the team members. For example, one member drew the conclusion: "The amount of learning materials is mentioned more often than the difficulty of the content." Another member responded to this by saying: "Well, they are not used to this, they do not encounter this in the lower grades."

Transitions from the internalization mode were made only to the externalization mode. These transitions occurred after the data team members reflected on the data team procedure or what they had done so far. They were initiated by the data team members, who then decided what data they were going to collect for their next meeting.

Content. Overall, the data team members discussed content related to data use as applied to the educational problem more often during their meetings than content related to the educational problem. Content about data use in general was rarely discussed. Only content about data use as applied to the educational problem was addressed in all four modes, whereas content about the educational problem and data use in general were addressed in all modes but the combination mode. Furthermore, each type of content was associated with its own dominant mode.

Content related to the educational problem was most often discussed in the socialization mode. During the interviews, the team members explained that they came to know that shortage points have an impact on grade retention. Furthermore, they

Figure 5.

The process of knowledge creation of team Lincoln, meeting 6

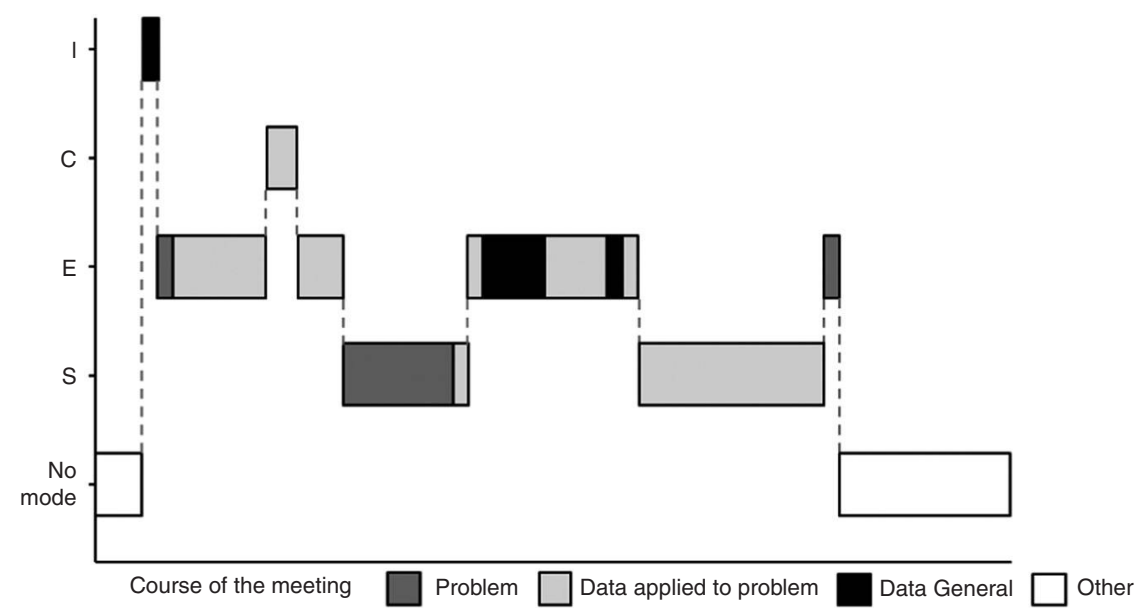


found out that teachers play a larger role in students' grade retention than expected, such as through a lack of classroom management skills. They also learned that some of their assumptions were false. As Ms Brown stated during the interview: "Those thoughts and assumptions we made, those just weren't the cause."

Content about data use as applied to the educational problem was discussed most often in the externalization mode. During the interviews, the team members stated that they had found out that there is a lot of data available in the school and that these data can help to invalidate preconceptions.

Content about data use in general was almost exclusively discussed in the externalization mode. During the interviews, the data team members explained they came to know that it is necessary to be concise in formulating a problem statement and collecting data. Furthermore, they found out that you have to check the quality of your data. When asked what they specifically learned about this, Mr Thomas, for example, said: "Well, that you have to do it."

Overall, data team members most often discussed content related to data use as applied to the educational problem. However, based on the interviews, it seemed that data team members only gained some knowledge about this type of data use, and gained most knowledge about the educational problem. They gained hardly any knowledge about data use in general, which aligns with the absence of this content during the meetings. Their learning gains about the educational problem became apparent in the number of examples of new knowledge they could list, and the depth of these examples. Thus, the overall extent to which a certain content was discussed was not necessarily indicative of what knowledge data team members gained. Rather, the extent to which this content was discussed specifically in the socialization and internalization mode seemed more indicative. Content about the educational problem was more often addressed in these modes than content about data use as applied to the educational problem and about data use in general. Thus, engagement in these two modes seemed to have added benefit for gaining new knowledge.

\section{Cross-case analysis}

The process of knowledge creation was studied in team Fairview and team Lincoln. The results of these within-case analyses were compared and contrasted with each other.

\section{Content}

The extent to which this content was discussed specifically in the socialization and internalization mode seemed to be of added benefit in the process of knowledge creation. All data team members gained most knowledge about the content for which they were predominantly or relatively often engaged in these modes. For Fairview, this was knowledge about the educational problem and about data use in general, and for Lincoln, this was knowledge about the educational problem; see Table III. In addition, team members gained less knowledge about content for which they were predominantly or exclusively engaged in the externalization mode. Both teams gained least knowledge about data use as applied to the educational problem, and team members from Lincoln also learned little about data use in general. Overall, in both teams knowledge gains for data use as applied to the educational problem and for data use in general were limited, and in some ways superficial. For example, nobody indicated having learned about data analyses. 


\section{JPCC \\ 1,1}

60

$\begin{array}{ll}\text { Fairview } & \text { Lincoln }\end{array}$

Mode S: brainstormed about hypotheses and measures, provided background information

E: discussed data collection and analyses

C: drew conclusions from data

I: reflected on data use, their findings and

their own learning process

More personal engagement in S and I

Transition Between meetings cyclical and in line with data teams procedure

Within meetings far more iterative

Transitions between all modes occurred

$\mathrm{S}$ to $\mathrm{E}$ and $\mathrm{E}$ to $\mathrm{S}$, provided background

information and shared personal

experiences, while data were collected/

analyzed/discussed

C to E, checked quality of data file while analyzing it

I to $\mathrm{E}$, reflected on learning process and

findings while the data file was discussed

Content Engagement in S and I of added value for

knowledge gains (educational problem and

data use in general)

Several examples with depth
$\mathrm{S}$ : brainstormed about new data collection and on measures

$\mathrm{E}$ : discussed data collection and analyses

C: drew conclusions from data

I: reflected on progress and data team

procedure

Less personal engagement in $\mathrm{S}$ and I

Between meetings cyclical and in line with data teams procedure

Within meetings more iterative

Transitions I to S, I to $\mathrm{C}$ and vice versa did not occur

$\mathrm{S}$ to $\mathrm{E}$ and $\mathrm{E}$ to $\mathrm{S}$, brainstormed about additional data collection, while data were collected/analyzed/discussed

$\mathrm{C}$ to $\mathrm{S}$, framed tentative conclusions about own experiences

I to $\mathrm{E}$, reflected on progress and data team

procedure while discussing the collection of additional data

Engagement in S and I of added value for

knowledge gains (educational problem)

Some examples without depth
Table III.
Results cross-case analysis

Note: S, Socialization; E, externalization; C, combination; I, internalization

Teams differed in their knowledge gains. Fairview's members could list more examples of what knowledge they had gained than Lincoln's members, and those examples had more depth. For example, the former listed several actions you must perform in order to get reliable data (e.g. specifying a good problem statement, collecting the right data), whereas the latter were only aware of the importance of having reliable and valid data. Taken together, it seems as if Fairview's process of knowledge creation was more beneficial than Lincoln's process. Therefore, similarities and differences in their modes and transitions will be explored in more detail.

\section{Modes}

Members from Fairview and Lincoln engaged differently in the SECI modes. When Fairview's members were engaged in the socialization mode, they did this in three main ways: by brainstorming about hypotheses, providing each other with background information on their schools' policy on grade demotion and by brainstorming about possible measures for improvement. Lincoln's members also brainstormed about possible measures, but were mainly engaged in the socialization mode to brainstorm about what additional data could be collected. The externalization mode looked quite similar, in that members from both teams discussed what measurements and data needed to be collected for what cohorts, and how they had to be processed. The combination mode also looked quite similar, in that members from both teams drew conclusions about data they had analyzed. But, teams differed in their engagement in the internalization mode. Fairview's members engaged in this mode to 
reflect on data use in general, on their own learning process, and on whether or not they were surprised by their findings. In contrast, Lincoln's members were engaged in this mode to reflect on the data team procedure and their progress, as they were concerned that their outcomes did not reflect what they wanted to know, and they were worried that they were progressing too slowly. Thus, both teams engaged in the externalization and combination mode similarly, whereas they differed in their engagement in the socialization and internalization modes.

As Fairview's team members gained most knowledge, it seems as though their

engagement in the socialization and internalization modes was more beneficial for the process of knowledge creation than Lincoln's engagement in these modes. The difference between the two teams is that Fairview's members seemed to be more personally engaged than Lincoln's members. The former paid attention to their intuitions and hunches and specifying a proper hypothesis, whereas the latter seemed more concerned with their working pace, and with continuously collecting more data without specifying a proper hypothesis for this. Thus, active personal engagement seemed beneficial for the process of knowledge creation.

\section{Transitions}

In both teams, transitions between meetings were more or less cyclical and were quite in line with the steps of the data team procedure. This pattern is visible regardless of whether the teams were using quantitative or qualitative data. However, concentrating on specific meetings revealed a more iterative knowledge creation process for Fairview than for Lincoln. For Fairview, transitions occurred between all modes. For Lincoln, transitions occurred between nearly all modes, the exception being that transitions between the internalization mode and socialization or combination mode (and vice versa) did not happen. Furthermore, there were some differences in the dominant transitions between the two teams.

At Fairview, transitions from the socialization mode to the externalization mode and vice versa occurred when data team members provided each other with background information on the school's policy on grade demotion and shared their personal experiences with these issues; that is, while collecting, analyzing or discussing their data files. These transitions were initiated by both team members and the coach. In contrast, these transitions were made at Lincoln to brainstorm about what additional data they wanted to collect; that is, while preparing research activities (e.g. creating a coding scheme) or discussing data files or analyses. Most of these transitions were initiated by the team members. Thus, Fairview's members were focussed on testing their intuitions about a certain cause after they had finished up with their previous test. In contrast, Lincoln's members were focussed on collecting data before finishing up their previous test, without articulating their intuitions as to a certain cause.

At Fairview, transitions from the combination mode to the externalization mode happened when conclusions were being drawn about the data. These transitions were most often initiated by the team members, and were directed at checking the quality of their data file. In contrast, transitions from the combination mode to the socialization mode happened at Lincoln to align (tentative) conclusions with team members' own experiences. Therefore, these transitions were always initiated by the team members. Thus, Fairview's members were aware of the importance of valid and reliable data in drawing conclusions, whereas Lincoln's members took this for granted, and mainly aligned their conclusions with their own experiences. 
JPCC 1,1

62

At Fairview, transitions from the internalization mode to the externalization mode were initiated after the team members reflected on their learning process or on whether they were surprised by their findings. The transitions were initiated by the team members themselves and were directed at discussing their data files. In contrast, at Lincoln, transitions were initiated after the data team members reflected on the data team procedure or on what they had done so far. The transitions were initiated by the team members, who then decided on what data they were going to collect for their next meeting. Thus, Fairview's members reflected on their own intuitions and learning process, whereas Lincoln's members reflected on their progress and the procedure as such. These findings on transitions align with the aforementioned findings on the modes, in that Fairview's members were personally engaged by testing and reflecting on their intuitions and learning experiences, whereas Lincoln's members were less personally engaged by collecting data, almost for the mere sake of collecting data, and reflecting on their progress and the procedure as such.

\section{Conclusions and discussion}

The present study explored how data team members created knowledge in terms of the modes and transitions in the SECI model. Furthermore, it determined what knowledge about the educational problem, data use as applied to the educational problem, and data use in general resulted from the knowledge creation process, and how this was related to the modes and transitions in the knowledge creation process. Several conclusions can be drawn.

\section{Modes}

In particular, the socialization and internalization modes had added value for the process of knowledge creation. Data team members learned most about content for which they were engaged in these two modes. Furthermore, teams engaged differently in these modes. This came across in the level of active personal engagement that was displayed, such as testing your own intuitions on the one hand (Fairview), and collecting additional data because you are concerned about your work pace on the other hand (Lincoln). In contrast, teams engaged similarly in the externalization and combination modes.

Even though the socialization and internalization modes might not seem especially relevant because they do not require "core, in depth" skills but "just" contain brainstorming sessions and reflective conversations, the present findings confirm the importance of these modes, and thus of tacit knowledge, in the SECI model (Nonaka, 1991). However, this does not mean that the externalization and combination modes are not relevant. It might mean that the value of engagement in these two modes depends on the level of personal engagement displayed in the socialization and internalization modes. For example, drawing conclusions (combination) will become especially valuable when team members are aware of what their intuitions about their hypothesis were (socialization), and actively ask themselves whether or not they are surprised by these conclusions (internalization).

Furthermore, the findings indicate that engagement in the socialization and internalization modes does not ensure successful knowledge creation, as the quality of engagement seems to be dependent of the level of personal engagement. Thus, working in the socialization and internalization mode seems especially beneficial when active personal engagement is displayed. 


\section{Transitions}

Regarding transitions, findings confirmed that the process of knowledge creation was more or less cyclical between meetings, which corresponds to the theory as posed by Nonaka et al. (2008). These transitions were quite in line with the steps of the data team procedure (Schildkamp and Poortman, 2015). For example, team members were often engaged in the socialization mode when they worked on steps 1 and 2 : defining a problem statement and hypotheses. However, when transitions within meetings were studied, the process of knowledge creation was more iterative, as hypothesized by Mandinach (2012). This means that transitions can occur between all modes.

Furthermore, the "micro transitions" within meetings differentiated between data teams' processes of knowledge creation. Teams differed in the extent to which their knowledge creation process was iterative, and what the dominant transitions were. Teams also differed in the context in which transitions occurred; for example, a transition from the socialization mode to the externalization mode and vice versa could occur to share personal experiences while collecting and analyzing data (Fairview) or to brainstorm about collecting additional data while still collecting and analyzing data on the previous hypothesis (Lincoln). Overall, the way in which transitions between the four modes happened was a differentiating factor between teams.

\section{Content}

It was concluded that content was especially gained after engagement in the socialization and internalization mode. Knowledge gains increased even further when data team members displayed personal engagement while working in these two modes. Overall, Fairview's members displayed more personal engagement and seemed to have gained more knowledge than Lincoln's members. For example, the former tested their intuitions, whereas the latter brainstormed about collecting additional data before finishing their previous research activities. This indicates that Lincoln's members did not have a clear goal for their use of data and were collecting data almost for the mere sake of collecting data. This is referred to as the "activity trap" (Katz et al., 2009), that is, data use that is well intended but not need based. Furthermore, results suggest that working pace is negatively related to working with the data team procedure, because even though Lincoln's members tested more hypotheses, their knowledge gains were smaller than those of Fairview's members. Thus, slower progress might be beneficial, as long as active personal engagement is displayed.

Overall, data team members gained more knowledge of the educational problem than of data use as applied to the educational problem and data use in general. This difference in knowledge gains between the educational problem and data use is not surprising, given the current accountability context in which data are often used to explain or defend certain actions or decisions (Datnow and Hubbard, 2015). The educational problem influenced data team members' daily working life, whereas they were novices at data use, which was not yet embedded in their daily working life. This could have led to a situation in which they felt committed to solving the educational problem, and using the data team procedure as a tool to achieve this.

\section{The process of knowledge creation}

The present study was one of the first attempts to make the process of knowledge creation a concrete and observable phenomenon. A starting point for opening the black box of knowledge creation was provided by illustrating the linearity and iterations of the process of knowledge creation, and by illustrating the importance
Knowledge creation in data teams 
JPCC 1,1

of engagement in the socialization and internalization mode and the level of personal engagement in so doing. These insights proved to be essential for understanding how educators gain knowledge of data use and how (teams of) educators can differ in this regard. These insights will also help in understanding educators' actual use of data, as their knowledge will influence this. These insights can be used to further support effective and sustainable use of data in education (Gerzon, 2015; Little, 2012).

\section{Practical implications}

The results suggest that it would be beneficial to stimulate active personal engagement while working in the socialization and internalization modes. This could be done by adding brainstorming sessions and reflective exercises that require such engagement to the manual about the data team procedure: for example, by requiring an explicit reasoning in the selection of an educational problem (step 1), and a hypothesis (step 2), and including reflective questions that support determining the quality of the data (step 4) and interpreting the analyses (step 6). This also requires that the data coach should stimulate this engagement. The coach should, for example, ask data team members reflective questions and ask them to use their personal experiences or intuitions to explain why they want to test a certain hypothesis: "I see my students' motivation drop after their first grade below passing. Therefore, we should study a hypothesis on student motivation."

Furthermore, the results suggest that more efforts need to be paid to increase knowledge gains about data use. Therefore, the coach could emphasize the value of data use for school improvement and instruction, whereas the accountability purpose should play a less central role. In so doing, specific attention needs to be paid to the transfer of the data team procedure from the team to teachers' daily working life.

\section{Limitations}

The present study had a few limitations. The first limitation is that the insights gained were based solely upon verbalizations during the knowledge creation process. This might be an underestimation of the process. For example, data team members might reflect on their findings without sharing their reflections with the entire team. However, as the process of the team as a whole was the main interest, it seems especially relevant to look at verbalizations, as that information is available to all team members. Furthermore, 45 meetings in total were studied and two cycles of interviews were conducted that confirmed the findings about the meetings. Therefore, it can be assumed that these findings provide an important initial understanding of the knowledge creation process. However, additional research is required, especially on less accessible and immediately visible processes of socialization and internalization. Second, it was difficult to trace the reasons for making "micro transitions" between modes within meetings, because team members and the coach often did not give an explicit reason why they were diverging from a certain topic. Still, transitions between modes could be described after an in-depth analysis of the meetings.

\section{Future research}

Future research on the process of knowledge creation should continue to use the SECI model. In doing so, particular attention needs to be paid to the added value of the socialization and internalization modes. As these two modes rely especially on tacit knowledge, which is difficult to verbalize, it might be useful to put additional efforts 
into distinguishing their occurrence. This can be done, for example, by probing team members with reflective questions at the end of each meeting, or by using a narrative storyline method, which requires team members to draw their experiences over time in a graph (e.g. Gergen and Gergen, 1988). In addition, research should illuminate how personal engagement influences the way in which these modes are enacted, and how this engagement can be stimulated. Furthermore, additional efforts are needed to relate the knowledge creation process to its outcomes. For example, it could be related to the sustainability of the data team procedure.

Even though several questions remain to be addressed, using the SECI model to study the process of knowledge creation can be considered a fruitful effort. The resulting insights are essential for understanding how educators gain new knowledge.

\section{Notes}

1. School and participant names are pseudonyms.

2. This is the percentage of students who complete their grade levels within the normal time-period, which is an indicator of educational quality. For example, if students enter the highest educational track and stay on that track until graduation without any delay, the rate is optimal. However, when students repeat a grade or transfer to a lower educational track, the rate drops.

3. There are three main educational tracks. The lowest track (four years - "vmbo") prepares students for vocational education. The intermediate track (five years - "havo") prepares students for college/higher education. The highest track (six years - "vwo") prepares students for university education. These tracks are quite segregated, which means that most students who enter a track stay within that track until graduation.

4. Grade demotion entails that students are transferred to a lower educational track, for example, from tenth grade "havo" to tenth grade "vmbo."

5. This placement advice is used in determining students' educational track in secondary education.

6. Students receive grades from 1 to 10 ; a 5 is equal to one shortage point, a 4 to two, etc. Thus, these shortage points indicate how far below passing students' grades are. The inverse of shortage points is excess points, see footnote 7 .

7. A grade of 7 is equal to one excess point, an 8 to two, etc.

\section{References}

Campbell, C. and Fullan, M. (2006), "Unlocking the potential for district wide reform”, available at: www.michaelfullan.ca/Articles_06/Articles_06a.htm (accessed May 12, 2015).

Carlson, D., Borman, G. and Robinson, M. (2011), "A multistate district-level cluster randomized trial of the impact of data-driven reform on reading and mathematics achievement", Educational Evaluation and Policv Analvsis, Vol. 33 No. 3, pp. 378-398.

Coburn, C.E. and Turner, E.O. (2011), "Research on data use: a framework and analysis", Measurement, Vol. 9 No. 4, pp. 173-206.

Datnow, A. and Hubbard, L. (2015), "Teachers' use of assessment data to inform instruction: lessons from the past and prospects for the future", Teachers College Record, Vol. 117 No. 4, pp. 1-26. 
JPCC 1,1

Datnow, A., Park, V. and Kennedy-Lewis, B. (2013), "Affordances and constraints in the context of teacher collaboration for the purpose of data use", Lournal of Educational Administration, Vol. 51 No. 3, pp. 341-362.

De Vries, B. and Pieters, J.M. (2007), "The knowledge-creating school proudly presents: a school community sharing its story", in Kimble, C., Hildreth, P. and Bourdon, I. (Eds), Communities of Practice: Creating Learning Environments for Educators, Information Age Publishing, Charlotte, NC, pp. 355-370.

Dutch Inspectorate of Education (2010), “'De Staat van het Onderwijs' ('The State of Affairs in Education')", Inspectie van het Onderwijs, Utrecht.

Eggen, T.J.H.M. and Sanders, P.F. (1993), Psychometrie in de Praktijk (Psychometrics in Practice), CITO, Arnhem.

Engeström, Y. (1999), "Expansive visibilization of work: an activity-theoretical perspective", Computer Supported Cooperative Work, Vol. 8 Nos 1-2, pp. 63-93.

Geertz, C. (1973), The Interpretation of Cultures: Selected Essays, Basic Books, New York, NY.

Gergen, K.J. and Gergen, M.M. (1988), "Narrative and the self as relationship", in Berkovitz, L. (Ed.), Advances in Experimental Social Psychology, Vol. 21, Academic Press, New York, NY, pp. 17-56.

Gerzon, N. (2015), "Structuring professional learning to develop a culture of data use: aligning knowledge from the field and research findings", Teachers College Record, Vol. 117 No. 4, pp. 1-28.

Hakkarainen, K., Palonen, T., Paavola, S. and Lehtinen, E. (2004), Communities of Networked Expertise: Professional and Educational Perspectives, Elsevier, Oxford.

Hargreaves, A. and Fullan, M. (2012), Professional Capital: Transforming Teaching in Every School, Teachers College Press, New York, NY.

Hargreaves, D.H. (1999), “The knowledge-creating school”, British Iournal of Educational Studies, Vol. 47 No. 2, pp. 122-144.

Katz, S., Earl, L. and Ben Jaafar, S. (2009), Building and Connecting Learning Communities: The Power of Networks for School Improvement, Corwin Press, Thousand Oaks, CA.

Kuiper, W., Van den Akker, J., Hooghoff, H. and Letschert, J. (2006), "Curriculum policy and school practice in a European comparative perspective", in Letschert, J.F.M. (Ed.), Curriculum Development Re-Invented. Proceedings of the Invitational Conference on the Occasion of the 30 years SLO 1975-2005, SLO, Enschede, pp. 56-77.

Lai, M.K. and Schildkamp, K. (2013), "Data-based decision making: an overview”, in Schildkamp, K., Lai, M.K. and Earl, L. (Eds), Data-Based Decision Making in Education: Challenges and Opportunities, Springer, Dordrecht, pp. 9-21.

Lai, M.K., McNaughton, S., Timperley, H. and Hsiao, S. (2009), "Sustaining continued acceleration in reading comprehension achievement following an intervention", Educational Assessment, Evaluation and Accountability, Vol. 21 No. 1, pp. 81-100.

Little, J.W. (2012), "Understanding data use practice among teachers: the contribution of microprocess studies", American Iournal of Education, Vol. 118 No. 2, pp. 143-166.

McFadyen, M.A. and Cannella, A.A. (2004), "Social capital and knowledge creation: diminishing returns of the number and strength of exchange relationships", Academv of Management Iournal, Vol. 47 No. 5, pp. 735-746.

Mandinach, E.B. (2012), "A perfect time for data use: using data-driven decision making to inform practice”, Educational Psvchologist 47 No. 2, pp. 71-85.

Marsh, J.A. (2012), "Interventions promoting educators' use of data: research insights and gaps", Teachers College Record, Vol. 114 No. 11, pp. 1-48. 
Nonaka, I. (1991), "The knowledge-creating company”, Harvard Business Review, Vol. 69 No. 6, pp. 96-104.

Nonaka, I. and Takeuchi, H. (1995), The Knowledge-Creating Company: How Japanese Companies Create the Dynamics of Innovation, Oxford University Press, New York, NY.

Nonaka, I., Toyama, R. and Hirata, T. (2008), Managing Flow: A Process Theory of the Knowledgebased Firm, Palgrave Macmillan, Hampshire.

Schaap, H., De Bruijn, E., Van der Schaaf, M.F. and Kirschner, P. (2009), "Student's personal professional theories in competence-based vocational education: the construction of personal knowledge through internalization and socialization", Iournal of Vocational Education and Training, Vol. 61 No. 4, pp. 481-494.

Schildkamp, K. and Kuiper, W. (2010), "Data-informed curriculum reform: which data, what purposes, and promoting and hindering factors", Teaching and Teacher Education, Vol. 26 No. 3, pp. 482-496.

Schildkamp, K. and Poortman, C.L. (2015), "Factors influencing the functioning of data teams", Teachers College Record, Vol. 117 No. 4, pp. 1-30.

Schildkamp, K. and Teddlie, C. (2008), "School performance feedback systems in the USA and in the Netherlands: a comparison", Educational Research and Evaluation, Vol. 14 No. 3, pp. 255-282.

Schildkamp, K., Poortman, C.L. and Handelzalts, A. (2015), "Data teams for school improvement", School Effectiveness and School Improvement. doi: 10.1080/09243453.2015.1056192.

Szulanski, G. (1996), "Exploring internal stickiness: impediments to the transfer of best practice within the firm", Strategic Management Journal, Vol. 17 No. 2, pp. 27-43.

Van den Bossche, P., Gijselaers, W., Segers, M., Woltjer, G. and Kirschner, P. (2011), "Team learning: building shared mental models", Instructional Science, Vol. 39 No. 3, pp. 283-301.

Verbeek, C. and Odenthal, L. (2014), “Opbrengstgericht werken en onderzoeksmatig leiderschap in PO en VO' ('DBDM and research leadership in primary and secondary education')", in Krüger, M. (Ed.), Leidinggeven aan Onderzoekende Scholen, Coutinho, Bussum, pp. 67-78.

Vescio, V., Ross, D. and Adams, A. (2008), "A review of research on the impact of professional learning communities on teaching practice and student learning", Teaching and Teacher Education, Vol. 24 No. 1, pp. 80-91.

Wayman, J.C., Midgley, S. and Stringfield, S. (2006), "Leadership for data-based decision making: collaborative educator teams", in Danzig, A., Borman, K., Jones, B. and Wright, B. (Eds), Learner-Centred Leadership: Research, Policy and Practice. Leadership, Lawrence Erlbaum, Mahwah, NJ, pp. 189-205.

Wenger, E. (1998), Communities of Practice: Learning. Meaning and Identity, Cambridge University Press, Cambridge.

Yeh, Y.C., Huang, L.Y. and Yeh, Y.L. (2011), "Knowledge management in blended learning: effects on professional development in creativity instruction", Computers and Education, Vol. 56 No. 1, pp. 146-156.

Yin, R.K. (2009), Case Study Research: Design and Methods, Sage Publications, Thousand Oaks, CA.

\section{Further reading}

Henry, S.F. (2012), Instructional Conversations: A Qualitative Exploration of Differences in Elementary Teachers' Team Discussions, Harvard University Graduate School of Education, Cambridge, MA.

Ministry of Education, Culture and Science (2000), Wet op het Onderwijstoezicht (Education Supervision Act), SDU, Den Haag.

Schildkamp, K. and Lai, M.K. (2013), “Conclusions and a data use framework”, in Schildkamp, K., Lai., M.K. and Earl, L. (Eds), Data-Based Decision Making in Education: Challenges and Opportunities, Springer, Dordrecht, pp. 177-192. 
JPCC

1,1

68

\section{About the authors}

Mireille D. Hubers, Msc is a $\mathrm{PhD}$ Student at the University of Twente, Institute for Teacher Training, and Professional Development, in the Netherlands. Her research interest concerns the influence of knowledge creation and knowledge sharing on the process of sustaining both school improvement and teachers' professional development, especially in the context of data-based decision making. Mireille D. Hubers is the corresponding author and can be contacted at: m.d.hubers@utwente.nl

Cindy L. Poortman, $\mathrm{PhD}$ is an Assistant Professor at the University of Twente, Institute for Teacher Training, and Professional Development, The Netherlands. Her main research interest concerns teachers' professional development in teams, such as data teams and teacher design teams.

Kim Schildkamp, $\mathrm{PhD}$ is an Associate Professor at the University of Twente, Institute for Teacher Training, and Professional Development, The Netherlands. Her research interests include data-based decision making, formative assessment and professional development. She has published widely in journals and edited books, and received grants, scholarships and awards for her work on data-based decision making. She is the developer of the data team procedure, which has been implemented in schools in the Netherlands, Sweden and England.

Jules M. Pieters, $\mathrm{PhD}$ is a Professor Emeritus of Applied Psychology at the University of Twente. He was involved in research projects on inquiry and collaboration in professional development of teachers, on co-designing of curriculum materials and learning environments by teachers in teacher design teams and on knowledge dissemination.

Adam Handelzalts, $\mathrm{PhD}$ is a Team Leader at the University Teachers College of VU University Amsterdam. His research interests concern teacher collaboration for professional development and school improvement.

For instructions on how to order reprints of this article, please visit our website: 